\title{
Evaluation of analgesic (in vivo) activity of Ariflex liniment in comparison with diclofenac gel by acetic acid induced writhing model
}

\author{
Sanjay U. Nipanikar ${ }^{1 *}$, Sohan S. Chitlange ${ }^{2}$
}

\author{
${ }^{1}$ Department of Research and Development, Ari Healthcare Private Limited, World Trade Center, Kharadi, Pune, \\ Maharashtra, India \\ ${ }^{2}$ Principal, Dr. D. Y. Patil Institute of Pharmaceutical Sciences and Research, Pimpri, Pune, Maharashtra, India
}

Received: 26 May 2021

Accepted: 29 June 2021

\section{*Correspondence:}

Dr. Sanjay Nipanikar,

Email: sanjay.n@arihealthcare.in

Copyright: (C) the author(s), publisher and licensee Medip Academy. This is an open-access article distributed under the terms of the Creative Commons Attribution Non-Commercial License, which permits unrestricted non-commercial

\begin{abstract}
Background: Adverse effects of available medications for osteoarthritis (OA) and rheumatoid arthritis (RA) necessitate development of safer and effective alternative medicinal substitutes. The present study was conducted to evaluate analgesic activity of Ariflex liniment (conceptualized and developed by Ari Healthcare Pvt. Ltd.) in comparison with diclofenac gel by using acetic acid induced writhing model.

Methods: Albino mice of either sex weighing 20-25 g were taken and divided into 3 groups with 5 animals in each group, i.e., group 1 (control group), group 2 (diclofenac gel) and group 3 (Ariflex liniment). After 1 hour of topical application of study drugs writhing was induced in mice using intra-peritonial injection of $1 \%$ acetic acid in volume of $0.1 \mathrm{ml} / 10 \mathrm{~g}$ body weight. Then the writhing episodes were recorded for 30 minutes and results were noted.

Results: In the control group, the total number of writhes were $260 \pm 29.73$ (mean \pm S. E. M.). The total number of writhes was $12.17 \pm 11.81$ (mean \pm S. E. M.) in diclofenac group. In Ariflex liniment group, not a single animal felt pain, hence there were no writhes recorded. When compared to control group, the difference in number of writhes was statistically significant. The analgesic activity of Ariflex liniment was found to be superior to that of diclofenac gel used as standard drug.

Conclusions: It can be concluded that Ariflex liniment possesses analgesic activity.
\end{abstract}

Keywords: Ariflex liniment, Diclofenac gel, Analgesic, Acetic acid induced writhing model

\section{INTRODUCTION}

RA is one of the common autoimmune diseases. It is a chronic progressive inflammatory disorder affecting the synovial joints and typically producing symmetrical arthritis. If the inflammation goes unchecked it can damage bones and cartilage of the joint leading to deformity and disability. Several treatments are available for RA including prolonged use of NSAIDs (non-steroidal anti-inflammatory drugs), DMARDs (disease modifying anti-rheumatic drugs), TNF inhibitors (tumor necrosis factor) and joint surgeries in severe cases. Though these medications are better treatment options for RA, the side effects of these medications such as osteoporosis, gastric ulcers, nephrotoxicity make them unsuitable for long term use. People tend to search alternative medicinal drugs for the management of pain and inflammation of joints. ${ }^{1,2}$

$\mathrm{OA}$ is the most common form of arthritis and is estimated to be the eighth leading cause of disability in the world..$^{2}$ It is more common in women than men. In India, OA is the most frequent joint disease with prevalence of $17 \%$ to $60.6 \%$ (Sharma et al 2007). ${ }^{3}$ Also it is second most common rheumatological problem in India. ${ }^{4}$

$\mathrm{OA}$ is a chronic degenerative joint disease characterized by loss of or injury to articular cartilage, sub-chondral thickening, hypertrophy of bone and alterations of the 
synovial membrane and joint capsule. ${ }^{4}$ In OA, bone rubbing causes pain, swelling and restricted range of motion at the affected joint. The joint may also lose its normal shape. In the normal adult, articular cartilage consists of a delicate system of cells and matrix proteins, which have the function of creating a viscoelastic tissue with high biomechanical stability and low friction. Articular cartilage remains stable, if the process of degeneration and regeneration of cells and matrix proteins occurs in equilibrium. Chondrocytes are the cartilage cells, which produce and maintain the cartilaginous matrix, which consists mainly of collagen and proteoglycans. The alteration of chondrocyte transplantation and degeneration of cartilage due to various triggering factors causes OA. ${ }^{5}$

Presently very few underlying factors are known to cause OA. But some common factors such as age, sex, obesity, genetics, bone density, smoking, local factors including trauma are main contributors in the pathogenesis of OA. OA with no known cause is termed as primary OA and it is mostly related to aging. Secondary OA results as a result of another disease or condition. The above mentioned factors initiate alterations in the equilibrium of cartilage formation and enhance degenerative cascade thus cause OA. ${ }^{4,5}$

Generally, OA is managed by symptomatic treatment methods such as use of pain and inflammation medications. NSAIDs (diclofenac, aceclofenac) and acetaminophen are considered to be the first line therapy in the management of OA. Selective COX II inhibitors are widely recommended by virtue of their efficacy and relatively lower adverse effects. Also, the symptomatic slow acting drugs for OA (SYSADOA) such as diacerein, hyaluronic acid (HA), chondroitin sulfate are useful in OA management. $^{6}$ In OA, intra-articular corticosteroid injections are believed to be most effective in patients with evidence of inflammation, effusion or both. Various other therapies such as transcutaneous nerve stimulation, thermal modalities, acupuncture and surgery (including joint replacement) have also been used to treat OA. Currently, though pharmacological, mechanical and surgical interventions are used, there is no known cure for OA. Also, above mentioned treatment options lead to many side effects and drawbacks. Topical formulations have relatively lower systemic adverse effects but greater cutaneous reactions when compared to oral NSAIDs. ${ }^{20}$
Thus, physicians and patients tend to move towards the use of alternative treatment methods. ${ }^{6-8}$

In the view of this situation, Ari Healthcare Pvt. Ltd. has conceptualized and developed Ariflex liniment to be applied externally for the management of joint pain and inflammation, muscle strain, muscle sprain and arthritis. It contains maha vishagarbha taila (ayurvedic classical formulation), gandhapura taila (Gaultheria fragrantissima), tailaparnah taila (Eucalyptus globulus), katuveera arka (Capsicum annuum), menthol (Mentha arvensis), karpoora (Borneo camphor) and linseed oil (Linum usitatissimum) as base..$^{9-15}$

In the present research work, an attempt has been made to evaluate the analgesic activity of Ariflex liniment in comparison with diclofenac gel by using acetic acid induced writhing model.

\section{METHODS}

\section{Study site}

The study was conducted at Padmashree Dr. D. Y. Patil institute of pharmaceutical sciences and research, Pimpri, Pune. The material used for the study is given in Table 1 .

Table 1: Materials used for the study.

\begin{tabular}{|ll|}
\hline Materials & Make \\
\hline Acetic acid & Merck \\
\hline Diclofenac gel & Novartis \\
\hline Ariflex liniment & Ari Healthcare Pvt. Ltd. \\
\hline
\end{tabular}

\section{Ethical consideration and approval}

Institutional animal ethics committee (IAEC) has approved the study in the meeting held on 31 Dec 2014. The approved protocol no. was DYPIPSR/IAEC/14-15/P03 .

\section{Study animals}

Male albino mice of 3-4 weeks age and having weight between 20-25 g were used in the study. The details are given in Table 2 .

Table 2: Animals used for the study.

\begin{tabular}{|llllll|}
\hline Sr. No. & Species & Age in weeks & Weight/size in g & Gender & Numbers to be used \\
\hline 1. & Albino mice & $3-4$ & $20-25$ & Male & 15 \\
\hline
\end{tabular}

\section{Analgesic activity of Ariflex liniment by using acetic acid induced writhing method}

Albino mice of either sex weighing 20-25 g were taken and divided into 3 groups with 5 animals in each group. Group 1 (control group) animals were starved overnight. Group 2 animals were topically applied with specified quantity of diclofenac gel as standard drug. Group 3 animals were topically applied with specified quantity of Ariflex liniment. After $1 \mathrm{hr}$ of topical application writhing was induced in mice by intra-peritonial injection of $1 \%$ acetic acid in volume of $0.1 \mathrm{ml} / 10 \mathrm{~g}$ body weight. Then the 
writhing episodes were recorded for 30 minutes and results were noted.

\section{RESULTS}

In the control group, the total number of writhes were $260 \pm 29.73$ (mean \pm S. E. M.) suggesting existence of pain.

The total number of writhes was $12.17 \pm 11.81$ (mean \pm S. E. M.) in diclofenac group, suggesting existence of very less pain. When compared to control group, number of writhes was significantly less in diclofenac group.

In Ariflex liniment group, not a single animal felt pain, hence there were no writhes recorded. When compared to control group, the difference in number of writhes was statistically significant. The details are presented in Table 3 and Figure 1.

Table 3: Number of writhes observed in different groups.

\begin{tabular}{|ll|}
\hline Groups & $\begin{array}{l}\text { No. of writhes }(\text { mean } \pm \text { S. E. } \\
\text { M.) }\end{array}$ \\
\hline Control & $260 \pm 29.73$ \\
\hline $\begin{array}{l}\text { Diclofenac } \\
\text { sodium }\end{array}$ & $12.17 \pm 11.81^{* *}$ \\
\hline Ariflex liniment & $0.0 \pm 0.0^{* *}$ \\
\hline
\end{tabular}

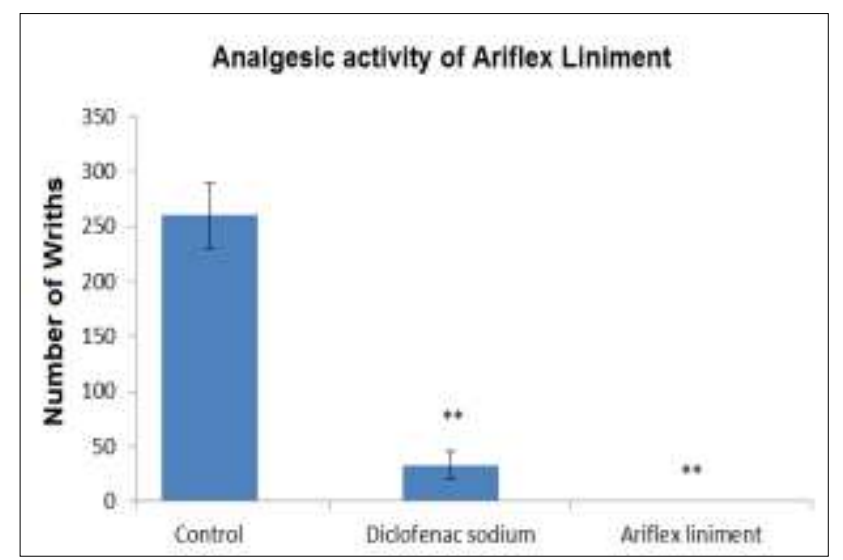

Data is expressed as mean $\pm \mathrm{S}$. E. M. of $\mathrm{N}=5$ observations; all treatments were compared with control (ANOVA followed by Dunnett's test) ${ }^{*} \mathrm{p}<0.05,{ }^{* *} \mathrm{p}<0.01$.

Figure 1: Analgesic activity of Ariflex liniment.

\section{DISCUSSION}

$\mathrm{OA}$ is a chronic degenerative joint disease characterized by loss of or injury to articular cartilage, sub-chondral thickening, hypertrophy of bone and alterations of the synovial membrane and joint capsule.

Various NSAIDS, analgesics, paracetamol, COX-II inhibitors that reduce pain and inflammation in OA and other drugs like chondroitin sulfate, diacerein, HA are generally used for the treatment of OA. Intra-articular steroid injection provides excellent symptomatic relief but fails to provide permanent relief. Various other therapies such as transcutaneous nerve stimulation, thermal modalities, acupuncture and surgery (including joint replacement) have also been used to treat OA. Though pharmacological, mechanical and surgical interventions are used, there is no known cure for OA. Also, above mentioned treatment options lead to many side effects and drawbacks like nephrotoxicity with diclofenac and hepatotoxicity with paracetamol, osteoporosis with corticosteroids on their long term irrational use. Hence patients tend to search safer and effective alternative therapeutic options. ${ }^{1}$

RA is one of the common autoimmune diseases. It is a chronic progressive inflammatory disorder affecting the synovial joints and typically producing symmetrical arthritis. If the inflammation goes unchecked it can damage bones and cartilage of the joint leading to deformity and disability. Several treatments are available for RA including prolonged use of NSAIDs, DMARDs, TNF inhibitors and in severe cases joint surgeries. Though these medications are better treatment options for RA management, the side effects of these medications such as osteoporosis, gastric ulcers, nephrotoxicity make them unsuitable for long term use. Hence people tend to search alternative medicinal drugs for the management of pain and inflammation of joints. ${ }^{1}$

Keeping in mind the need of the time to have drugs with minimum side effects, Ari Healthcare Pvt. Ltd. has conceptualized and developed Ariflex liniment for the treatment of arthritis.

In the present study evaluation of analgesic activity (in vivo) of Ariflex liniment in comparison with diclofenac gel in acetic acid induced writhing model was done. Results of the study indicate that both the formulations possess strong analgesic activity. The analgesic activity of Ariflex liniment was found to be superior to that of diclofenac gel used as standard drug.

Ariflex liniment contains maha vishagarbha taila (ayurvedic classical formulation), gandhapura taila ( $G$. fragrantissima), tailaparnah taila (E. globulus), katuveera arka (C. annuum), menthol (M. arvensis), karpoora ( $B$. camphor) and linseed oil (L. usitatissimum) as base. ${ }^{9-15}$

Maha vishagarbha taila is medicated oil composed of more than 50 different herbs. In Ayurveda, its use is recommended in various vatavyadhis (musculoskeletal disorders). Its topical application over affected area is said to relieve the stiffness (sarvangagraha). ${ }^{9}$

Gandhapura taila (G. fragrantissima) is widely used topically in the management of various types of arthritis. ${ }^{16}$ Methyl salicylate and its glycoside derivatives obtained from this species are reported to possess remarkable antiinflammatory and analgesic properties. ${ }^{10}$ 
Tailaparnah taila (E. globulus) is a volatile oil obtained from E. globulus, traditionally used in the treatment of upper respiratory tract infections, wounds, fever and rheumatism. Anti-inflammatory and analgesic activities of Eucalyptus oil are reported by various studies. ${ }^{11}$

Katuveera arka is obtained from $C$. annuum. The active ingredient capsaicin is supposed to be responsible for its pharmacological activities. Capsaicin binds to specific receptors/nociceptors in the skin, which initially causes a state of neuronal excitation and a period of increased local sensitivity. This results in burning sensation, stinging and itching associated with cutaneous vasodilation. These manifestations are attributed to the stimulation of afferent C-fibers and the release of substance P. Soon after, a refractory period occurs with reduced sensitivity. Depletion of substance P and degeneration of peripheral nerve fibres occurs on repeated application and reduced sensitivity persists. Its effectiveness in treating pain associated with OA and RA is documented. ${ }^{17}$

Menthol is obtained from the oil of plant M. arvensis. Methanolic extracts of this plant are reported to possess significant anti-inflammatory and anti-arthritic activities in experimental studies. ${ }^{18}$ Menthol is a topical vasodilator that enhances the absorption of other topical skin medications. It is said to stimulate the cold receptors on the skin and dilate the blood vessels causing cooling and analgesic effects. Menthol in low concentration causes cooling sensation and the same when applied topically in high concentration causes local anesthesia and pain relief. It is also reported to reduce histamine induced irritation and itching in some studies. ${ }^{19}$

Karpoora is obtained from the plant B. camphora. Camphor is a known agonist of TRPV2, TRPA1 and TRPV1 quickly deactivating TRP channels. This results in long-term pain relief. It is a relatively weak sensory irritant having a modest excitatory effect on thermo-sensitive (and perhaps nociceptive) cutaneous fibers. ${ }^{14}$

Studies have reported that combination of menthol with camphor enhances skin penetration of methyl salicylate and inhibits both in vivo and in vitro synthesis of methyl salicylate to salicylic acid. ${ }^{14}$

Linseed oil is obtained from dried ripe seeds of $L$. usitatissimum. It is a rich source of $\alpha$-linolenic acid which is proved to possess noticeable anti-inflammatory activity. Anti-inflammatory, analgesic and anti-oxidant properties of this edible oil are confirmed in various studies. Its topical use has been approved in various dermatological conditions. ${ }^{15}$

Many ingredients of Ariflex liniment possess analgesic activity in isolation and hence the synergistic action of these herbs could have contributed to the strong analgesic effect of Ariflex liniment.

\section{CONCLUSION}

It can be concluded that Ariflex liniment possesses analgesic activity. Ariflex liniment can be used in the management of joint pain and inflammation, muscle strain, muscle sprain.

Funding: No funding sources

Conflict of interest: None declared

Ethical approval: The study was approved by the Institutional Ethics Committee

\section{REFERENCES}

1. Hochberg MC, Altman RD, April KT, Benkhalti M, Guyatt G, McGowan J, et al. American college of rheumatology 2012 recommendations for the use of nonpharmacologic and pharmacologic therapies in osteoarthritis of the hand, hip, and knee. Arthritis Care Res (Hoboken). 2012;64(4):465-74.

2. Nam JL, Wunthro KL, Vollenhoven RFV, Pavelka K, Valesini G, Hensor EMA, et al. Current evidence for the management of rheumatoid arthritis with biological disease-modifying antirheumatic drugs: a systematic literature review informing the EULAR recommendations for the management of RA. Ann Rheum Dis. 2010;69(6):976-86.

3. Radha MS, Gangadhar MR. Prevalence of knee osteoarthritis patients in Mysore city, Karnataka. Int J Rec Scientif Res. 2015;6(4):3316-20.

4. Mahajan A, Verma S, Tandon V. Osteoarthritis. JAPI. 2005;53:634-41.

5. Tallheden T, Bengtsson C, Brantsing C, Carlsson L, Peterson L, Brittberg $\mathrm{M}$, et al. Proliferation and differentiation potential of chondrocytes from osteoarthritic patients. Arthritis Res Ther. 2005;7(3):560-8.

6. Scheinfeld N. A comprehensive review and evaluation of the side effects of the tumor necrosis factor alpha blockers etanercept, infliximab and adalimumab. J Dermatolog Treat. 2004;15(5):280-94.

7. Kongtharvonskul J, Anothaisintawee T, McEvoy M, Attia J, Woratanarat P, Thakkinstian A. Efficacy and safety of glucosamine, diacerein, and NSAIDs in osteoarthritis knee: a systematic review and network meta-analysis. Eur J Med Res. 2015;20(1):24.

8. Tascioglu F, Armagan O, Tabak Y, Corapci I, Oner C. Low power laser treatment in patients with knee osteoarthritis. Swiss Med Wkly. 2004;134(1718):254-8.

9. Shastri B. Yogaratnakar with Vidyotini commentary. commentary by Shastri L, Poorvardha. Varanasi: Choukhamba Prakashan; 2012: 531.

10. Liu W, Qiao W, Liu Z, Wang X, Jiang R, Li S, et al. Gaultheria: phytochemical and pharmacological characteristics. Molecules. 2013;30;18(10):12071108.

11. Silva J, Abebe W, Sousa S, Duarte V, Machado M, Matos F. Analgesic and anti-inflammatory effects of 
essential oils of eucalyptus. J Ethnopharmacol. 2003;89(2-3):277-83.

12. Hernández-Ortega M, Ortiz-Moreno A, HernándezNavarro M, Chamorro-Cevallos G, Dorantes-Alvarez L, Necoechea-Mondragón H. Antioxidant, antinociceptive, and anti-inflammatory effects of carotenoids extracted from dried pepper (Capsicum Annuum L.). J Biomed Biotechnol. 2012;2012:524019.

13. Sá RDCDSE, Andrade LN, Sousa DPD. A Review on Anti-inflammatory activity of monoterpenes. Molecules. 2013;18(1):1227-54.

14. Silva-Filho SE, Silva-Comar FMDS, Wiirzler LAM, Pinho RJ, Grespan R, Bersani-Amado CA, et al. Effect of camphor on the behavior of leukocytes in vitro and in vivo in acute inflammatory response. Tropic $\mathbf{J}$ Pharmaceut Res. 2014;13(12):2031-7.

15. Hashempur MH, Homayouni K, Ashraf A, Salehi A, Taghizadeh M, Heydari M. Effect of Linum usitatissimum L. (linseed) oil on mild and moderate carpal tunnel syndrome: a randomized, double-blind, placebo-controlled clinical trial. DARU. 2014;22(1):43.

16. Chunekar KC. Bhavaprakasha Nighantu of Bhavamishra. Chaukhambha Publications; 2010: 809.

17. Flores MP, Castro A, Nascimento J. Topical analgesics. Rev Bras Anestesiol. 2012;62(2):244-52.

18. Reddy V, Rao G, Lakshmi G. A review on antiarthritic activity of some medicinal plants. J Glob Trend Pharmaceut Sci. 2014;5(4):2061-73.

19. Balakrishnan A. Therapeutic uses of peppermint-a review. J Pharmaceut Sci Res. 2015;7(7):474-6.

20. Nair B, Taylor-Gjevre R. A review of topical diclofenac use in musculoskeletal disease. Pharmaceuticals. 2010;3(6):1892-908.

Cite this article as: Nipanikar SU, Chitlange SS. Evaluation of analgesic (in vivo) activity of Ariflex liniment in comparison with diclofenac gel by acetic acid induced writhing model. Int $\mathrm{J}$ Basic Clin Pharmacol 2021;10:943-7. 